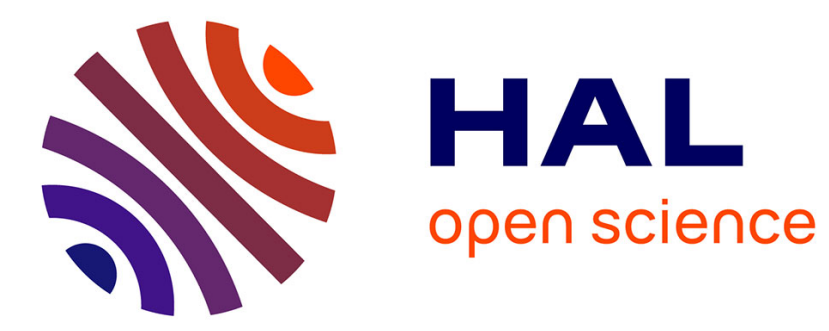

\title{
Proposition of a communication system used in mobility by users with physical disabilities, focus on cerebral palsy with athetoid problems
}

\author{
Yohan Guerrier, Christophe Kolski, Franck Poirier
}

\section{- To cite this version:}

Yohan Guerrier, Christophe Kolski, Franck Poirier. Proposition of a communication system used in mobility by users with physical disabilities, focus on cerebral palsy with athetoid problems. International Conference on Advanced Logistics and Transport - ICALT'2013, May 2013, Sousse, Tunisia. 6 p. hal-00826040

\section{HAL Id: hal-00826040 \\ https://hal.science/hal-00826040}

Submitted on 1 Sep 2013

HAL is a multi-disciplinary open access archive for the deposit and dissemination of scientific research documents, whether they are published or not. The documents may come from teaching and research institutions in France or abroad, or from public or private research centers.
L'archive ouverte pluridisciplinaire HAL, est destinée au dépôt et à la diffusion de documents scientifiques de niveau recherche, publiés ou non, émanant des établissements d'enseignement et de recherche français ou étrangers, des laboratoires publics ou privés. 


\section{Proposition of a communication system used in mobility by users with physical disabilities, focus on cerebral palsy with athetoid problems}

\author{
Yohan Guerrier, Christophe Kolski \\ Univ Lille Nord de France, F-59000 Lille \\ UVHC, LAMIH, F-59313 Valenciennes \\ CNRS, UMR 8201, F-59313 Valenciennes \\ Yohan.guerrier@gmail.com \\ christophe.kolski@univ-valenciennes.fr
}

\author{
Franck Poirier \\ Laboratoire UMR Lab-STICC \\ Université de Bretagne Sud \\ F-56000 Vannes \\ Franck.Poirier@univ-ubs.fr
}

\begin{abstract}
This paper presents an on-going research about a new system of communication for people with cerebral palsy $(\mathrm{CP})$ with athetoid problems. These people have gestural and speech difficulties; so they need help for communicating with people and systems. The system proposed is called CотMOB (COMmunication means for MOBility). Its user interface is based on pictograms to accelerate the input. Moreover, the aim is that this system is context sensitive.
\end{abstract}

Keywords-Communication; mobility; Disabled user; Cerebral palsy (CP); Slurred speech; Communication support

\section{INTRODUCTION}

Communication is part of the important acts performed by any human being in his/her life. Communication can build relationships while accessing to information and knowledge. However, at this level, everyone is not equal, to the extent that we can identify many handicaps, and this in two distinct categories: mental and physical [12].

In this article, we focus on the physical one and especially on users with Cerebral Palsy (CP) with athetoid problems (profile of the first author). These people have the particularity to have involuntary movements, which greatly reduce movement precision [8]. The main source of this type of disability is a lack of oxygen, or during childbirth or during the first hours of their live, having resulted in damage to neurons [8]. Within the two categories of disability, several handicaps may cause slurred speech. Concerning the mentally disabled, their problems lie in the fact that they find it difficult to make a correct sentence. However, within the category of physical disability, difficulties in articulation may be more or less important. CP may be associated with athetoid disabilities that cause slurred speech: these people have no problem to formulate sentences, but the words coming in their mouths are distorted due to dysarthria [15].

Law No. 2005102 on 11 February 2005 [9] aims to accessibility for persons with disabilities to public facilities and public transport. In this new legal framework, it is necessary to find solutions to the problem of communication of individuals with disabled motor pronunciation difficulties. In this context, it is important to provide a communication support for users with CP.

The article begins with a state of the art about different communication supports for people with CP. Then, different communication needs of such users are presented. Then our current works concerning an assistive communication system, called ComMOB, are explained. The article ends with a discussion followed by a conclusion.

\section{RELATED WORKS}

At first we will describe different virtual keyboards, and then present some speech recognition systems and conclude with input systems without keyboard. Different systems will be analyzed as follows: system description, strengths and weaknesses, both in relation to the following user profile: athetoid CP. It is important to mention here that BrainComputer Interfaces (BCI) are not taken into account in our study because they cannot perform complex communication tasks; likewise, optical motion tracking is not possible due to the uncontrolled movements of the people with cerebral palsy.

\section{A. Virtual keyboards}

Virtual keyboards are the basic element of the input assistance in the field of physical disability. They can be grouped into different categories. Firstly, so-called optimized virtual keyboards as KThot [1] or UKO2 [13] are available. These keyboards are designed to reduce the movements of the mouse, and thus increase the speed of typing.

Other keyboards focus on the prediction of words or letters. We can cite the following keyboards: Chewing Word [4], Sibylle [10], K-hermes [5], KEYGLASS [11]. All these keyboards include a set of principles to make entry faster.

More, several keyboards use primitives to allow the user to enter several letters simultaneously. We can cite HandiGlyph [3]. It proposes a set of syllables through several symbols, Figure 1 (b). 
However, despite the various researches and advances in the field, the virtual keyboard input is slow and tiring. Four examples of virtual keyboards are visible on Figure 1.

(a)

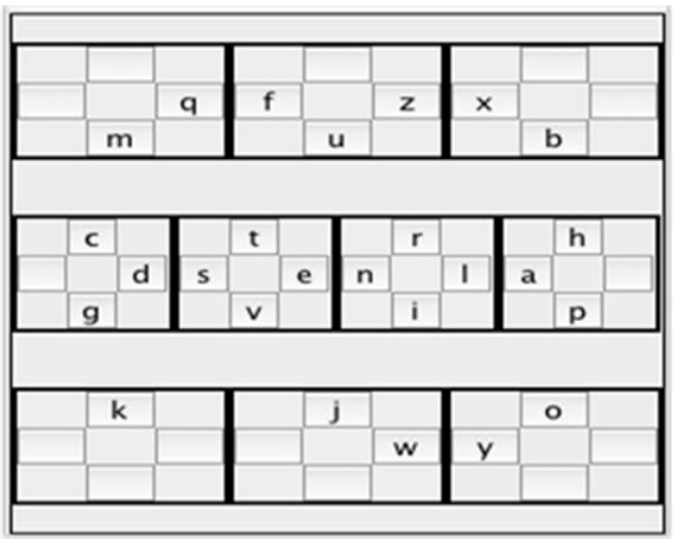

(b)

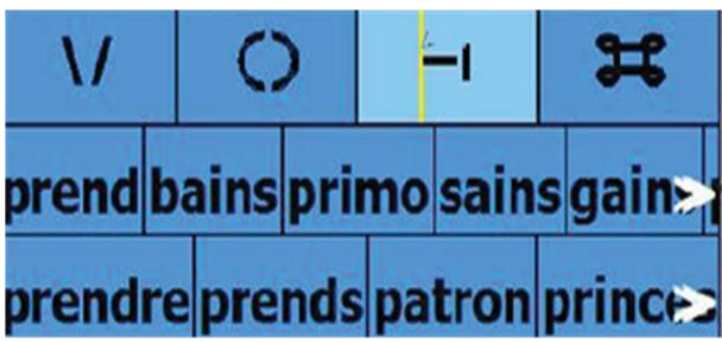

(c)

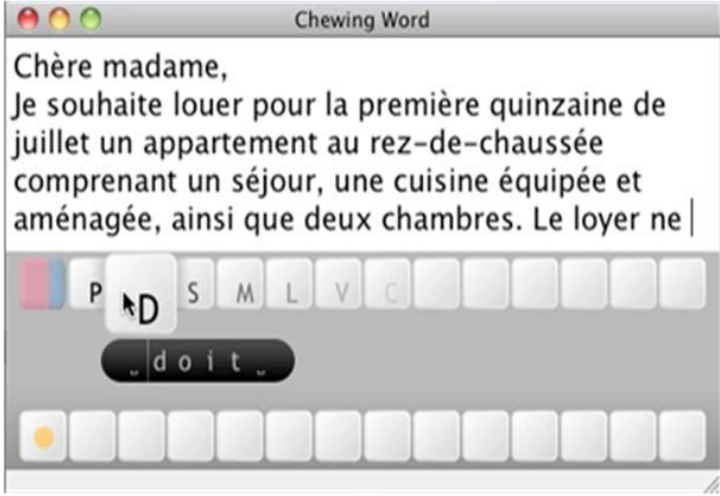

(d)

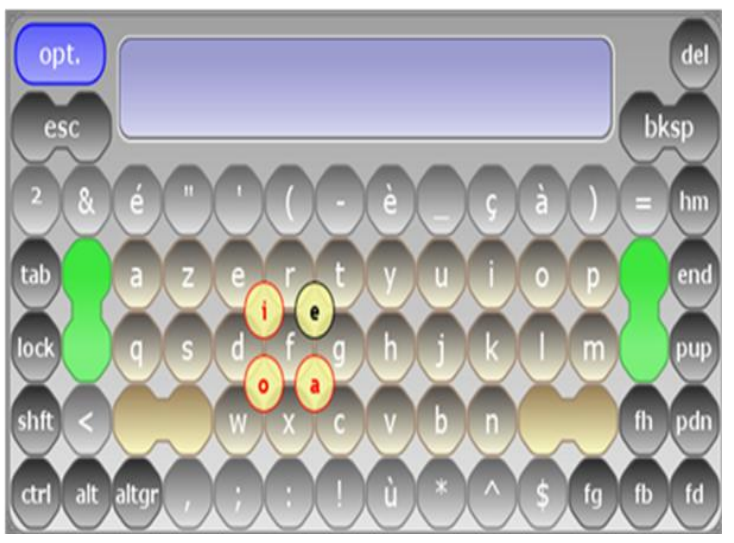

Figure 1. Four examples of virtual keyboards: KThot optimized (a), HandiGlyph (b), Chewing Word (c), KEYGLASS (d)

\section{B. Physical entry systems for people with physical disabilities}

This section lists a set of input aids that do not belong to the domain of software keyboards, and can therefore complement the previous category.

EdgeWrite [17]: this is a recording system using the joystick movements. The user forms letters through the joystick movements. This process accelerates the input, because there is no mouse movement. This process is only for CP users without athetoid symptom.

Entering row / column with two buttons [2]: on the screen, a virtual keyboard is shown as a rectangle; the user has two physical buttons, one for rows and one for columns. This principle is intended for individuals with severe motor disabilities. If the user knows the coordinates of the letters by heart, input can be very fast. Input requires additional cognitive effort to count the contact line / column of each letter

Guide finger [7]: this system consists of a perforated plastic plate at the locations of keys on a physical keyboard. This allows the user to press the desired key without making mistakes. The main advantage of this system is the ability to use any physical keyboard. The finger guide is not easy to use by all users with athetoid problems: it depends if the disabled person has learned to use it during his/her childhood when his/her brain still had a significant plasticity [8].

\section{Speech recognition}

The third category concerns essentially speech recognition:

Speech recognition for users with CP [16]: voice recognition system is adapted to recognize how people with $\mathrm{CP}$ speak. The recognition algorithm retrieves the voice of people with disabilities into the wave, then normalizes it to get as close as possible to a wave of the voice of a person without a disability. However, the error rate of the voice recognizer stays very important.

\section{Conclusion on the studied systems}

We have proposed a state of the art of a set of resources currently available to support communication for individuals with athetoid CP. Each of these systems has advantages and disadvantages in relation to such user profile. To summarize, virtual keyboards allow them to enter a short text with a relatively low level of fatigue, while voice recognition gives individuals with $\mathrm{CP}$ the opportunity to enter quickly without any physical effort, but are penalized by their high error rate, more or less frequent depending on the systems and their contexts of use.

Virtual keyboards have the disadvantage of slowing the entry and request a considerable physical effort when the texts are long to grasp. Speech recognition is not yet fully adapted for people with significant speech problems. Other systems require a too high level of precision in movements for a person with athetoid $\mathrm{CP}$.

We believe that virtual keyboards will always stay a slow and challenging way for people due to the frequent uncontrolled movements applied to the mouse. The perfect 
solution would be a voice recognition completely adapted to their way of speaking, but the knowledge and current technologies can not achieve an operational voice communication system actually.

We must find a new way for assistive communication system for users with athetoid CP. This is the subject of the next section.

\section{P RÉSENTATION OF NEEDS IN COMMUNICATION THEMES FOR USERS WITH CEREBRAL PALCY}

In this section, a representative list of tasks that a disabled person with cerebral palsy may achieve in every day live is given (without particular order or priority):

- $\quad$ Buy products (online or not)

- Write and read different types of documents

- $\quad$ Ask for help

- Make a payment

- Communicate with people (in certain cases on forum or social network)

- Send and consult emails

- Navigate on the Internet

- Program

Note that the last task (To Program) refers to a business need in case the user is also computer scientist (case of the first author of this paper). These tasks involve oral or written means of communication.

Such list allows us to understand human tasks for which communication supports may be useful for users with athetoid $\mathrm{CP}$ and have to be designed.

\section{SPECIFICATION OF THE COMMOB SYSTEM}

\section{A. Presentation of ComMOB}

In this section, we present a research in progress on a software communication support, called ComMOB (COMmunication means for MOBility); this system is being designed. ComMOB is part of the doctoral thesis of the first author of this article. This research aims to realize a communication support based on pictograms. ComMOB is dedicated to disabled users with athetoid $\mathrm{CP}$, and particularly with speech problems. These users do not have a mental disability. We chose the pictograms to allow quick text entry using virtual keyboards. The difficulty is not only to make the software easy to use from the user interface point of view: the user has also to be efficient in his/her communication tasks. Indeed, we are interested in people with motor disability of $\mathrm{CP}$ athetoid type. These users have involuntary movements; this reduces their accuracy in their actions through the user interface. The software communication support will be used on a tablet computer, which is intended to be installed directly on the wheelchair of the user. We chose a tablet computer to make a compromise between the size and the display surface.
For this project, we focus on transport. Everyone who uses transport means is required to make requests (e.g., request for a ticket). For a person who has speech problems, this action is very complicated, and even sometimes impossible. ComMOB has to be context-sensitive by using location information. For example, if the user is in a transport station then ComMOB must propose pictograms primarily related to transport in general and stations in particular. The software will also allow the disabled person to work during trips; activities could even concern software development if the user is a computer scientist (such as the first author). The system must give the possibility to call a person for help through a button in case of problem(s). In parallel, a warning message will be displayed on the screen and delivered using speech synthesis. Another objective is to help the disabled user with speech problems to hold a conversation in public transport.

In conclusion the support system must enable a disabled person with cerebral palsy (and in consequence with speech difficulties) to use public transport means autonomously (without human assistance). In case of problem(s), the disabled user should have the possibility to directly use ComMOB to find a solution.

\section{B. User needs}

Figure 2 represents the needs (from task list given in section III) of a user with CP profile, concerning oral and written communication, in different situations (on the move; or fixed in position, for instance at work).

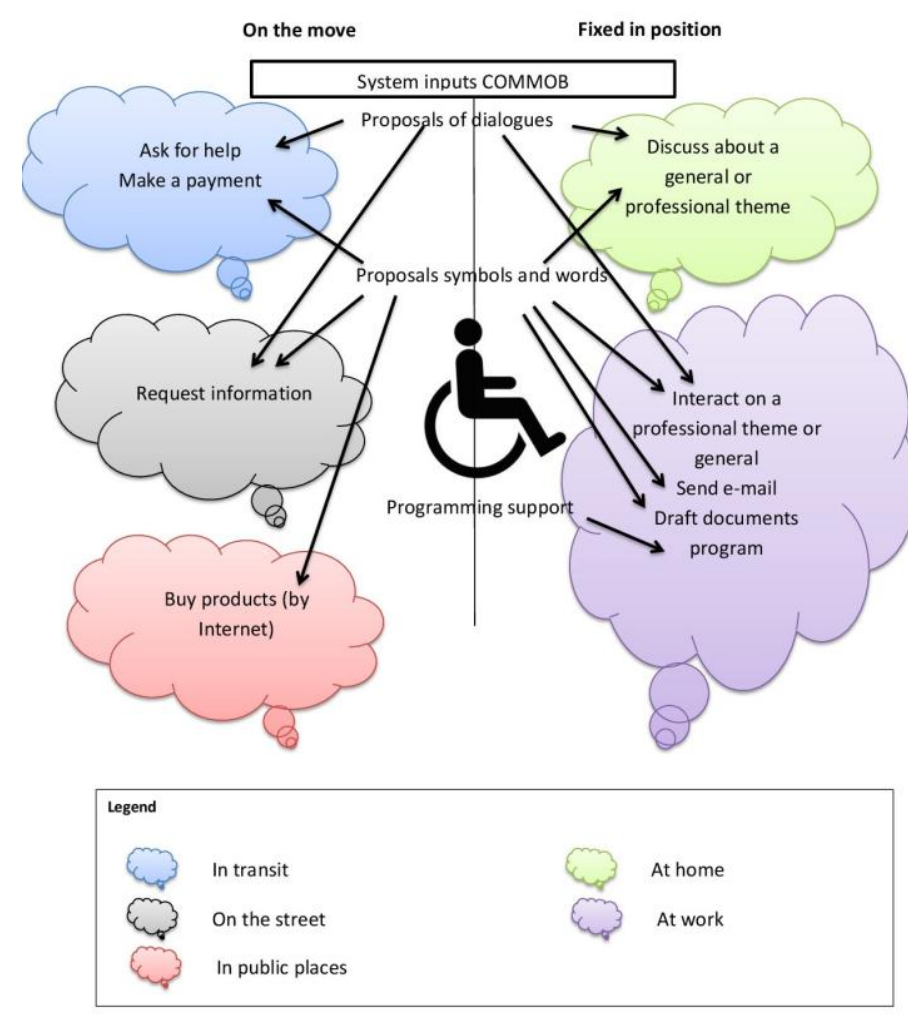

Figure 2. Contributions of the ComMOB system 
Concerning situations in mobility, the user can be mainly in transport where the communication is very present. He or she can make requests for information (for example in a station) but also for objects or food, and so on (for example in a shop).

In addition, many mobility situations may be at risk because the smallest problem can become very complicated to handle for a disabled person, hence the importance to find assistance. We associate user needs defined above with software functions. Each module of ComMOB must meet a specific need of the disabled person. These needs are grouped into themes; for example the Figure 2 shows a theme called "On the street". This one regroups a set of communication needs of a disabled person with $\mathrm{CP}$ in such situations. Obviously, certain needs can be placed several times in different bubbles visible on the Figure 2. However, we chose to put them only in the most representative bubble so as not to overload the figure 2 .

\section{Design models}

Figures 3 and 4 show several UML activity diagrams which detail the functioning of the proposed system.

The figure $3 \mathrm{a}$ shows the start-up sequence of the software. The figure $3 \mathrm{~b}$ describes the alarm mode: it is initiated by the user pressing the alarm button; it triggers a text message and sound. The figure $3 \mathrm{c}$ explains the virtual keyboard mode that allows the user to type words not represented by symbols (see also Figure 6). a)

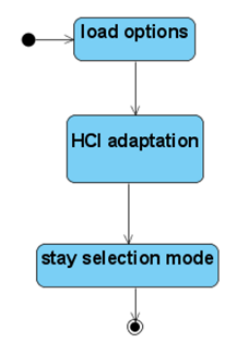

c)

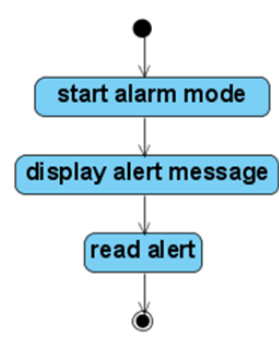

Figure 3. Activity diagrams showing: (a) option mode, (b) keyboard mode, (c) alarm mode

Figure 4 is intended to explain the operation of three modules: "pictogram icon", "scanning" and "dialog preparation."

The "pictogram icon mode" module is used to formulate sentences from symbols (as illustrated in Figure 5). The "scan" module is used to show a colored rectangle. This rectangle in

turn selects all the symbols. This feature allows the message recipient to select pictogram icon. When the rectangle highlight changes on the pictogram icon desired by the user, the user makes a movement of the head for the message recipient to validate. This is necessary because the $\mathrm{CP}$ users are sensitive to stress and this greatly increases the number of involuntary movements and therefore reduces their accuracy. The "dialogue preparation" module is aimed at giving the possibility to the user to prepare his or her sentences in advance to make the future dialogue more fluid.

a)

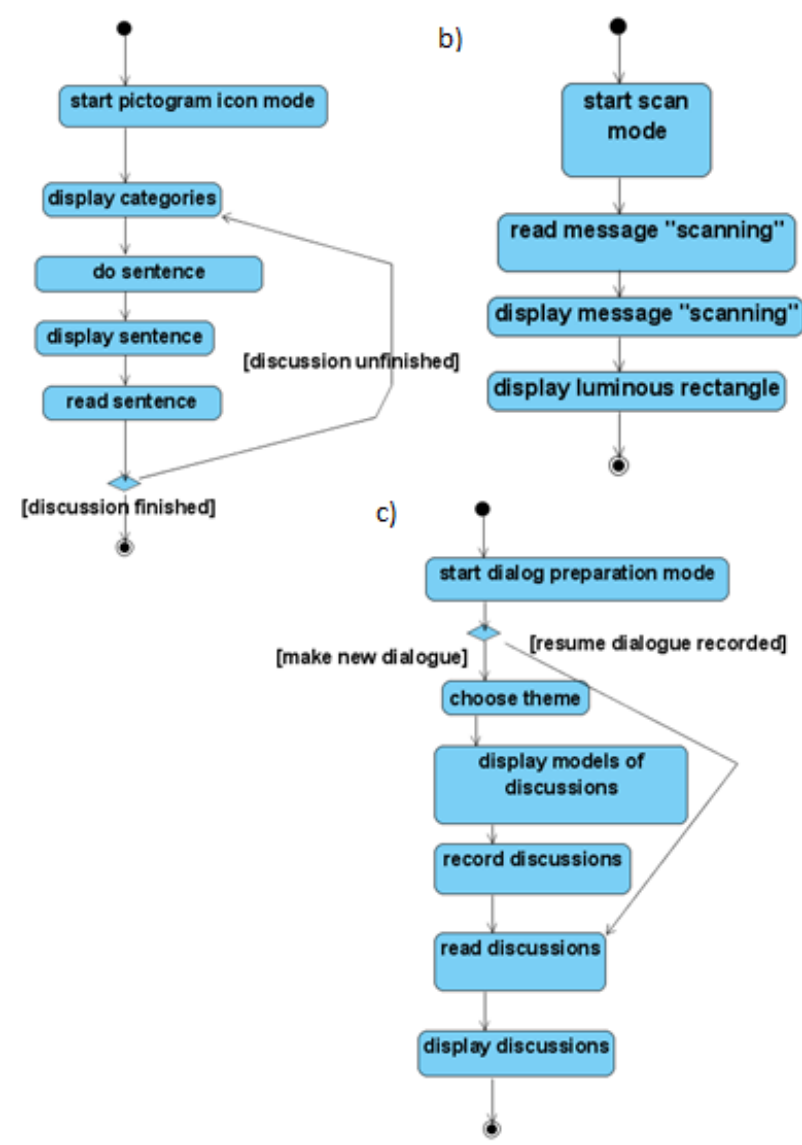

Figure 4. Activity diagrams showing: (a) pictogram icon mode, (b) scan mode, (c) dialog preparation mode

\section{Hardware}

The software is available on a tablet computer, which runs Windows 7. The tablet computer chosen is a HP Slate. This tablet computer has a screen of 8.9 inches $(23 \mathrm{~cm})$.

The user moves the mouse pointer with the joystick placed directly on the wheelchair. The connection is made through the casing which is located above the handle. Information flows in the infrared. The tablet computer has a USB port that allows us to connect the infrared system to control the cursor with the joystick of the wheelchair. The validation is done through a button next to the joystick (Fig. 7 (a)).

The ComMOB system is currently in a phase of prototyping. It is written in Java. This choice was also a reason 
for rapid development. In fact, under Windows (and using Java) we can easily find modules already developed which can be reused or adapted. In addition, the size of the tablet computer allows its installation on the wheelchair and its use in public transport.

\section{E. Illustrations}

The Fig. 7(b) shows a disabled user exploiting ComMOB for communicating with a person; in this situation this user requests information about schedules and connections concerning the tram and buses in the city of Valenciennes, France.

Figure 5 shows an example of a formulation of sentence from several pictograms [19]. We can see that the number of symbols is lower than the number of words. This can greatly accelerate the text entry.

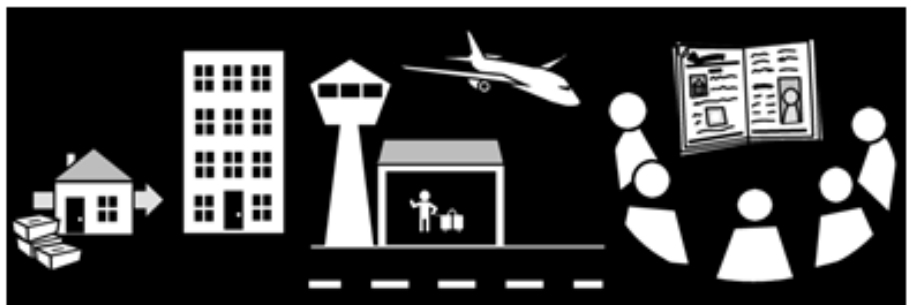

Je

I go to the airport to go to the conference

Figure 5. Example of formulation of a sentence from pictograms

The figure 6 shows another example: a formulation of sentences from pictograms associated with words; for complementary text entry, the use of a virtual keyboard is necessary. Indeed, some words cannot be represented by pictograms; we can cite as an example the names of cities or airport names. The user must complete the dots using the virtual keyboard: in this case Clavicom $N G$ [20]. This keyboard provides the user with a set of predicted words to accelerate the entry.

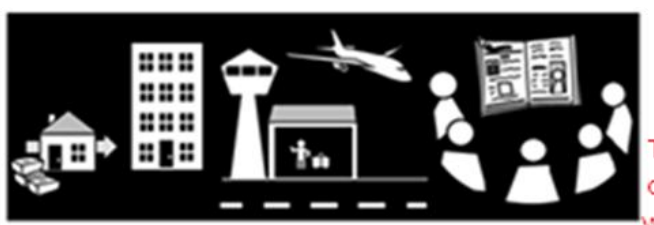

The userfills the dotted lines with Igo to the ....... airport to go to the ....... conferenced be proposed by th

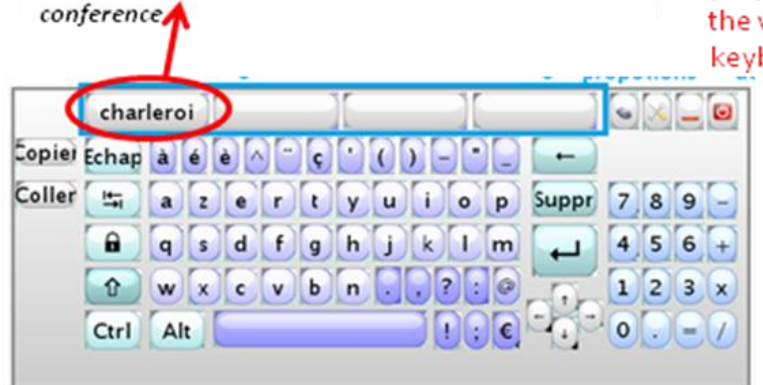

Figure 6. Example of formulation of a sentence from words and pictograms (a)

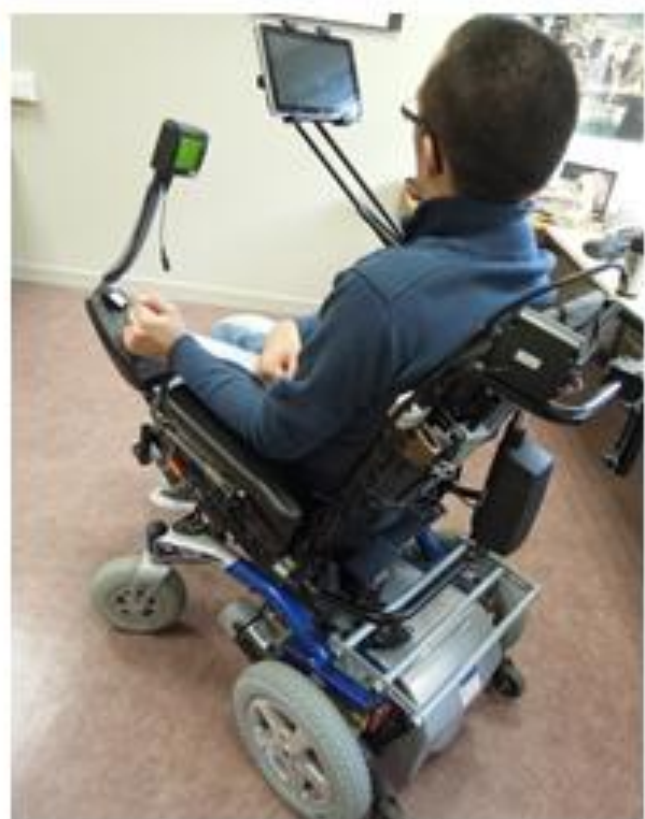

(b)

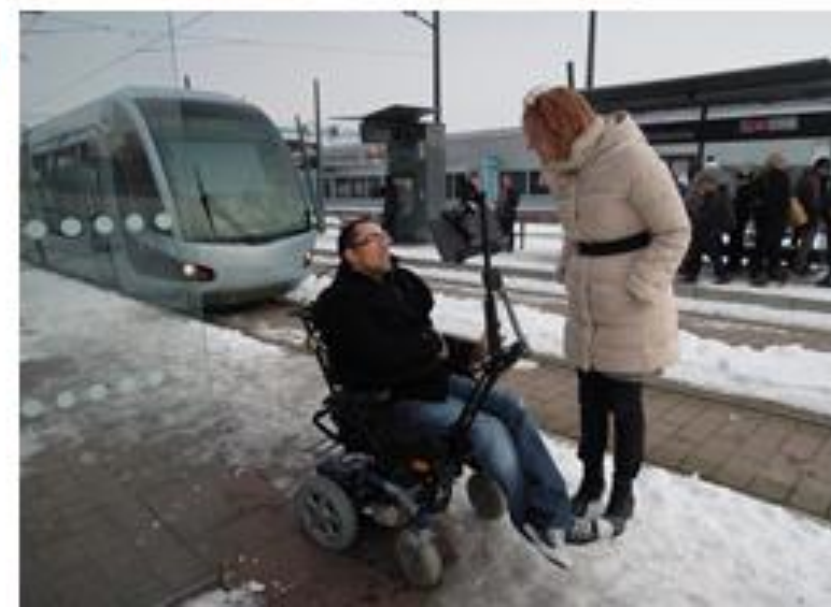

Figure 7. ComMOB used in two different situations

\section{DISCUSSION AND FUTURE WORK}

There are several types of communication system for users with CP. Most commonly used are virtual keyboards because they are relatively simple to use. However, they do not allow quick text entry and they require physical effort during use; these problems are still present despite numerous researches in this domain.

In general, the physical communication supports are really effective when used from early childhood, when the brain still has high plasticity.

Voice recognition system is ideal for people with disabilities because it requires very little physical effort during use. However, speech recognition is not yet suitable for users with CP because the error rate is too high.

For these reasons we are working on a software communication system, called ComMOB, considering several 
needs of users with CP. This system has been designed; it is currently in a phase of prototyping.

We plan to perform a series of user tests with the communication system in order to compare it with existing software in the market for such as MIND EXPRESS [18]. This software allows formulating sentences with pictograms; but in fact this software is primarily intended for mentally disabled people. These tests aim to formulate a set of usages in mobility in public transport. The test issues with pictograms. The goal is to retrieve a set of data for comparison. We can cite the following data to be used in the comparison: the time taken to formulate a sentence error rate, the rate of correct response to the questions asked, the number of selected pictograms, the number of entered words.

These measures will be expressed using the standard metrics of the domain (keystrokes per character, words per minute, letters per minute) [14].

\section{ACKNOWLEDGMENT}

This research work has been supported by CISIT, the NordPas-de-Calais Region, and the European Community (FEDER).References

[1] Baas, M., Guerrier, Y., Kolski, C., Poirier, F. Système de saisie de texte visant à réduire l'effort des utilisateurs à handicap moteur. Proceedings of the Ergonomie et Informatique Avancée Conference (12-15 october), ACM Press (2010), Biarritz, 19-26.

[2] Baljko, B., Tam, A. Indirect Text Entry Using One or Two Keys. Proc. ASSETS'06, Portland, Oregon, USA, October 22-25, ACM Press (2006).

[3] Belatar, M., Poirier, F. Text entry for mobile devices and users with severe motor impairments: handiglyph, a primitive shapes based onscreen keyboard. Proc. ACM ASSETS, Halifax, Canada, October, 209-216
[4] Grange, A. L'interface du clavier virtuel Chewing Word. Actes d'IHM'10, 22e Conférence Francophone sur l'Interaction HommeMachine, September, ACM Press (2010), 237-240.

[5] Guerrier, Y., Baas, M., Kolski, C., Poirier, F. Comparative study between AZERTY-type and K-Hermes virtual keyboards dedicated to users with cerebral palsy. In C. Stephanidis, Universal Access in Human-Computer Interaction: Users Diversity, UAHCI 2011, LNCS 6766, Springer, pp. 310-319.

[6] Guerrier Y., Kolski C., Poirier F. (2012). Comment communiquer lorsqu'on est un utilisateur infirme moteur cérébral (IMC) de type athétosique ? Etude de cas des différents moyens de communication. Proc. of the ERGO-IHM Conference (17-19 october), ACM, Digital Library, Biarritz, pp. 51-54.

[7] http://djtechtools.com/2012/08/19/momentary-fx-in-ableton-liveadvanced-midi-mappings/

[8] http://cerebralpalsy.org/about-cerebral-palsy/what-is-cerebral-palsy/

[9] http://www.legifrance.gouv.fr/affichTexte.do?cidTexte=JORFTEXT000 000809647\&dateTexte

[10] http://.info.univ-tours.fr/\%7Eantoine/SIBYLLE/Sibylle_en/index.html

[11] http://keyglass.free.fr/

[12] http://web.jhu.edu/disabilities/faculty/types_of_disabilities/

[13] http://wiki.cogain.info/index.php/UKO-II

[14] MacKenzie, I. S. Soukoreff, R. W. Text entry for mobile computing: Models and methods, theory and practice. Human-Computer Interaction, 17, pp. 147-198 (2002).

[15] O'Sullivan, S. B.; Schmitz, T. J. (2007). Physical rehabilitation (5th ed.). Philadelphia: F. A. Davis Company.

[16] S. Suanpirintr, N. Thubthong. The Effect of Pauses in Dysarthric Speech Recognition Study on Thai Cerebral Palsy Children. ACM New York, NY, USA, Icreate, 2007.

[17] Wobbrock, J.O., Myers, B.A., Aung, H.H., LoPresti H.F. Text Entry from Power Wheelchairs: EdgeWrite for Joysticks and Touchpads. ASSETS' 04, Atlanta, GA, USA, ACM Press (2004), 110-11

[18] /www.cimis.fr/handicap-moteur/aide-a-la-communication/mind-express4.html

[19] www.cndp.fr

[20] www:code.google.com/p/clavicom/ 